\title{
Conceptualizing humanistic management as an alternative to managing in a post crisis world
}

\author{
Michael Pirson ${ }^{\mathrm{a}, \mathrm{b}, *}$ \\ ${ }^{a}$ Schools of Business Director, Center for Humanistic Management, Fordham University, NY, USA \\ ${ }^{\mathrm{b}}$ Research Fellow, Harvard University, New York, USA
}

\begin{abstract}
The various crises require a different paradigm for business theory and practice. For this special issue contributors were asked to conceptualize such an alternative paradigm and propose and discuss heretofore unnamed phenomena. We present six contributions from renowned experts in the field that argue for a shift in perspective of management and organizational research and practice to allow us to conceptualize a life-conducive economic system.
\end{abstract}

Keywords: Humanistic management, paradigm, post-crisis world, alternative business

\section{Introduction}

The manifold crises evidenced by Global Financial collapse, exacerbating climate change, the everincreasing social inequity within so-called developed economies and the increasing loss of public trust in business have long called the current paradigm of economics into question. The underlying economic paradigm influences not only policy makers but also everyday practitioners and therefore academics are challenged to provide better and more accurate theory. Management theory is accused of being practically irrelevant and serving a few particular interests instead of the interests of the public $[1,8,10]$. Despite the Academy of Management's (AOM) mission and objective to "foster [] a philosophy of management" that

\footnotetext{
*Corresponding author: Michael Pirson, Ph.D. Associate Professor, Fordham University, Schools of Business, Director, Center for Humanistic Management, Fordham University, Research Fellow, Harvard University, Suite 1146, 5 Columbus Circle, New York, NY, 10019, USA. Tel.: +1 718817 1000; Fax: +1 718817 4001; E-mail: pirson@fordham.edu.
}

serves "the public's interests" [4] management scholarship' contribution to the public good has been neglected [10]. Very few contributions discuss managerial solutions to environmental degradation, the dangers of climate change, or increasing social inequities [7, 8]. Witnessing this lack and the inability of current theorists to develop cohesive and substantive answers leads some to argue that we are experiencing a prelude to a paradigm change $[3,9]$. Since we cannot satisfactorily address the current problems with the theories at our disposal, management scholars have long been called to re-conceptualize their basic, paradigmatic assumptions $[6,7]$. However, as William Allen, the former chancellor of the Delaware Court of Chancery, notes, "[o]ne of the marks of a truly dominant intellectual paradigm is the difficulty people have in even imagining an alternative view" [2]. Given the consequences of the last financial crisis and the path-dependent stability of old paradigms, we need to find ways to create new pathways of thinking so we can inform better practice.

This special issue of Human Systems Management is providing a space to create such new pathways for management theorizing. As the mission of HSM 
states, it aims to promote research at the interface of effective organizing (the science of management) and the art of management linking human beings and their creative potential to solving real-world problems through enterprise, leadership, innovation and participation. A specific focal point of HSM is the gap between academic theorizing and real-world managerial needs. While many academics still debate the trade-off between relevance and rigor, some Past Presidents of AOM are increasingly questioning the "mess we are in [5]." As they have suggested, management theory needs to provide real life value [8], but theories can only be as good as their underlying paradigm allows. In this special issue we thus challenged academics to stop the navel-gazing and suggest theoretical frameworks that can help understand and mitigate the current crises. We also invited public thought leaders as well as practitioners and policy makers to openly discuss alternative paradigms for economics, business and management.

As such we wanted to provide a space in this special issue for naming and discussing both new and previously unnoticed phenomena. We hoped to develop a better vocabulary and language that will allow for a true repositioning of the economic sphere and the managerial role. We were specifically interested in conceptualizations that embrace non-linear, qualitative, procedural alternatives including the protection of human dignity and the promotion of sustainable wellbeing. We invited solid theoretical, philosophical and conceptual papers that challenge the existing paradigms of economics and management, and that provide not only a critique, but also a real debatable alternative.

As a result, we have chosen six contributions that we feel answered our call for papers best. These six papers outline various perspectives that have so far received less attention than they deserve. These papers name phenomena that have been understudied or neglected and provide starting points for more research and theorizing that can help in this post-crisis world: from the focus on novel narrative creation (Hunter Lovins) to the foundations of a sustainable economic system (Shann Turnbull), to the pillars of a humanistic management paradigm around human dignity (Claus Dierksmeier) and human well-being (Ricardo Aguado, Leire Alcañiz, and Josá Luis Retolaza) to a new theory of a (managed) firm (JC Spender) to a novel concept for democratic governance in corporations (Michael Pirson and Shann Turnbull). As many observers suggest the question is not IF but WHEN the next crisis will strike again. So, for all those academics concerned, we have our work cut out for use and we need to engage in thoughtful debates around alternative paradigms of organizing. We hope this special issue can catalyze some of those necessary conversations.

\section{Contributions to this special issue}

To guide the overall conversation, the special issue starts with a contribution by Hunter Lovins, the noted public intellectual and thought leader for sustainable business practice. She suggests in her piece that a first step out of our mess is to recreate the narrative of business. She suggests that we need to have a better story of what business stands for and how it can be part of the solution and lead towards a life-conducive economic system. She argues, that "The global economy rests on a knife-edge. It is based on unsustainable business practices that are driving societies and ecosystems into successive collapses. There are many palliative "fixes" that can prop the system up - but only for a time. What is needed is a new development paradigm, one based on recognizing that the economy depends wholly on preserving a healthy ecosystem. The current paradigm, based on what Randy Hayes calls Cheater Capitalism, ${ }^{\mathrm{i}}$ in which incumbent technologies are subsidized, corporate profits are socialized and the too-big-to-fail are bailed out" does not convince anymore. She continues by suggesting that the challenge facing the world is a question of story, invoking Thomas Berry: "We need a story that will educate man, heal him, guide him."'ii She then lays out the cornerstones of this better story and the underlying principles that can get theory, practice, and policy moving towards a better, regenerative economy.

Shann Turnbull, the prolific scholar on corporate governance outlines his perspective on drivers for a life-conducive economic system which he labels ecological capitalism. In his contribution he argues that a better system and a universally prosperous environmentally sustainable global society are incompatible with traditional economic policies dependent on full employment and ideologies based on uninhibited use of non-renewable resources. He suggests that "politically attractive incentives of smaller taxes and government can be a way of changing the functioning of the economy so that prosperity can be increased even with a declining and aging population." The key to his ideas are the localization of ownership and control of the means of production and exchange. He also suggests that we create a "universal minimum social dividend to replace the need for full employment, welfare, pensions, and 
big government." In addition, local democracy needs to be enriched with the power to nurture the respective host environment. That "hyper" localization according to Turnbull will be achieved by ecological forms of cost carrying money redeemable into local services of nature which allow market forces to encourage production techniques that reduce their environmental impact. These ideas seem radical and have been tested and proven only in marginal contexts, yet may be the basis for a better, more life-conducive system.

Claus Dierksmeier, a noted philosopher and leader of the Global Ethic Institute of the prominent theologian Hans Kueng, proposes a shift of concepts to bring about better management theory. He suggests that we move away from imitating the positivist approach of the natural sciences in management and engage proactively with the normative, ethical foundations of business. Dierksmeier argues that management theory "should set sail towards the shores of a humanistic paradigm, centered on the idea of human dignity." He says: "To understand human agency we must penetrate the normative dimension of the human mind. Descriptions of economic behavior match reality only when they are observant to the moral prescriptions that inform said behavior." Referring back to the history of economic thinking he suggests we reconnect with the wisdom of ages, philosophy and ethics. He develops his thesis in favor of a new management theory centered on the idea of human dignity in the following steps: (1) He investigates how in 19th century the introduction of mechanistic models of human behavior, like the homo economicus-theorem, economic thinking impacted and impaired modern management theory. (2) Then, in order to prepare the philosophical grounds for a future humanistic management theory, he gleans the central normative tenets of a humanistic ethics from the history of philosophy. (3) Last, he investigates the possible contributions of a humanistic paradigm, centered on the idea of human dignity, to guide research, practice and pedagogy.

As a second cornerstone of humanistic conceptualizations of management, Ricardo Aguado, Leire Alcañiz and José Luis Retolaza are proposing alternative objective functions for the firm examining the current discourse on well-being in economics. They suggest that at the macro-level, different institutions (OECD, WEF, UN) have already developed sound methodologies in order to measure the economic, social and environmental impacts of economic activity. They argue that at the micro-level (level of the firm), it is crucial to develop a methodology in order to measure how firms are contributing to human dignity and social welfare by generating value for stakeholders. They suggest shifting common accounting principles which are mainly focused on annual profit/loss, in order to contribute to shareholders' interest and pay taxes to public administrations. They therefore argue that accounting models have to be complemented with a new approach that could assess stakeholders about the value that firms are generating while interacting with them: "The accounting process should be able to quantify not only profits, but also the impacts of firms on suppliers, customers, the environment, local communities, workers' quality of life, employment and the overall society." In their paper they develop such an accounting model that is able to monetize all those interactions and impacts in a way that is comparable, auditable, understandable and possible to be used by firms of all size using case examples.

In a further contribution, JC Spender then proposes a new theory of the firm that may help give shape to the above presented philosophical and normative ideas. Spender is dissecting old micro economic perspectives of the firm and suggests that they are at best incomplete in understanding and informing the tasks of real-life managers. By introducing the Knightian uncertainty principles as well as bounded rationality, he suggests we need to understand the notion of the managed firm better, in which actors are not fully informed but need to move from decision making to judgment. He proposes that understanding the firm as a bundle of judgment and opportunity spaces could be helpful in addressing the real nature of firms and theorizing about it that way would make the study and practice of firms more accurate, real, ethical and possibly humane.

Finally, Pirson and Turnbull present a short outline on how such judgment perspectives could be used for better corporate or firm governance. They argue that organizations in our time need a different way to manage themselves. A network of stakeholders as those people interested in the maintenance of the organization need to work together in a manner that shares power and decision making along the lines of the democratic checks and balances. Such a shift has occurred in many democratic societies of yore but still has to occur for the remnant of feudal structures: limited liability corporations. The format of governance proposed called network governance is practiced in the many cooperative firms to some degree and in some capitalistic organizations such as The John Lewis Partnership in the UK or Mondragon in Spain. However, management theory is remarkably blind to such phenomena and so is the discourse of practitioners and policy makers. 


\section{Call for conversation}

All in all we present in this special issue six articles that outline radical principles and theoretical avenues which we offer for further exploration. We understand that they are only raw attempts. Yet, they get the reader thinking about fundamental shifts in our understanding of what a good economic system is and how we can manage organizations better so that we ultimately achieve a world in which we protect human dignity better and are able to provide avenues for human flourishing and well-being including for the unborn generations. I encourage responses to these articles and discussions and though pieces are welcome as comments. Please direct to: pirson@ fordham.edu.

\section{References}

[1] Aguinis, H., and Pierce, C. A., Enhancing the relevance of organizational behavior by embracing performance management research. Journal of Organizational Behavior 29 (2008), $139-145$.
[2] Allen, W. T., Contracts and communities in corporation law. Washington \& Lee Law Review 50 (1993), 1395-1407.

[3] Anderson, N., The incubator: The people make the paradigm. Journal of Organizational Behavior 19(4) (1998), 323-328.

[4] Editors, A., Editor's Preface. Academy of Management Journal 1(1) (1958), 5-6.

[5] Freeman, E. W., J., SBE/SIM joint speaker reception: James Walsh. SBE/SIM Annual Gathering 2014, Philadelphia (2014).

[6] Gladwin, T. N., Kennelly, J. J., and Krause, T. S., Shifting paradigms for sustainable development: Implications for management theory and research. Academy of Management Review 20(4) (1995), 874-907.

[7] Hahn, T., Kolk, A., and Winn, M., A new future for business? Rethinking management theory and business strategy. Business \& Society 49(3) (2010), 385-401.

[8] Hambrick, D., What if the Academy actually mattered? Academy of Management Review 19(1) (1994), 11-16.

[9] Kuhn, T., The Structure of Scientific Revolutions. University of Chicago Press (1996).

[10] Walsh, J. P., Weber, K., and Margolis, J. D., Social issues and management: Our lost cause found. Journal of Management 29(6) (2003), 859-881.

iRandy Hayes, "Rethinking Society From the Ground Up," www.asap4all.org, in articles.

${ }^{i i}$ http://www.journeyoftheuniverse.org/storage/The_New_Story.pdf. 